\title{
OXFAM GB'S \\ GENDER PAY GAP \\ REPORT \\ For 5 April 2017
}

The Equality Act 2010 requires organizations with more than 250 staff to report on their gender pay gap. Oxfam GB welcomes this legislation and shares the steps it is taking to address its own gender pay gap. We confirm that the information contained in this report is accurate.

SIGNED MARK GOLDRING, CEO, AND TINA PROUDLOCK, PEOPLE DIRECTOR, OXFAM GB

This report can be downloaded from www.policy-practice.oxfam.org.uk 


\section{CONTENTS}

FOREWORD

1 Understanding gender pay gaps and their drivers

1.1 The gender pay gap: what is it and how does it differ from equal pay?

1.2 What are the common drivers of gender pay gaps?

2 OXFAM GB'S GENDER PAY GAP

10

2.1 Oxfam's organizational structure and how it relates to the gender pay gap

2.2 Leadership in the workplace

2.2.1 Recruitment and gender bias in the workplace

2.3 Unpaid care work

2.3.1 Maternity, paternity and adoption leave

2.3.2 Enabling more part-time work, job shares and flexibility 17

2.3.3 Women over 40

2.3.4 Mental health and self-care

2.4 Gendered jobs and wider sectoral trends

2.4.1 Trading roles

2.4.2 Information systems 


\section{FOREWORD}

The gender pay gap is just one example of the discrimination that holds back women around the world. It is also one of the barriers we need to break down if we are to beat inequality and poverty for good. That's why women's economic empowerment is a cornerstone of the United Nations' Sustainable Development Goals (SDGs) - and a key element of Oxfam's work with women and girls worldwide.

The gender pay gap is about more than equal pay, as it is a measure of the difference between men's and women's average earnings across an organization. The higher a gender pay gap figure, the more likely it is that there are proportionately more women in lower paid roles and/or more men in higher paid roles.

While there has been some progress towards greater equality between women and men around the world, the pace of change has been too slow and the economic gap between women and men is on the rise. For example, the time that it will take for women and men to be employed at the same rates, paid the same for equal work, and have the same levels of seniority, has increased in the past year alone from 170 years to 217 years. ${ }^{1}$

\section{THE GENDER PAY GAP AT OXFAM GB}

As an organization that is working to enable women to realize their rights, Oxfam GB is determined to build a fairer and more equal world for everyone - and of course that starts here, with us. Oxfam simply should not have a gender pay gap and should aim to achieve a zero pay gap. However, it is not simple, as gender pay gaps are a result of many factors, some of which are within Oxfam's control and some are due to wider societal norms that need to be challenged. There is more that we need to understand before making a commitment to achieve a zero gap. We have therefore set a two-year timeframe to address key areas of concern and increase our understanding to inform a longer term target and approach.

We are committed to going significantly beyond the reporting requirements to address our own gender pay gap which on 5 April 2017 was 11\% (mean) and 12.5\% (median). Our reported figure, as per regulations, includes our UK staff and a small proportion of international staff. Because our trading and our development and humanitarian arms operate separately, we have also separated our analysis for the purposes of reviewing the gender pay gaps in each. When we analyse them separately, we have the following gender pay gaps:

- $7.12 \%$ (mean) and $2.03 \%$ (median) for Trading

- $10.6 \%$ (mean) and $9.8 \%$ (median) for our international non-government organization (INGO)

While most international employees do not fall under the gender pay gap reporting requirements for the UK, Oxfam GB is committed to transparent reporting, irrespective of where our employees are based. Recognizing the complexities of cross-country pay analysis, we commit to presenting meaningful data on the representation of women by level across all countries we work in for next year's report. 


\section{OXFAM GB'S TWO WORKING MODELS AND GENDER PAY GAP}

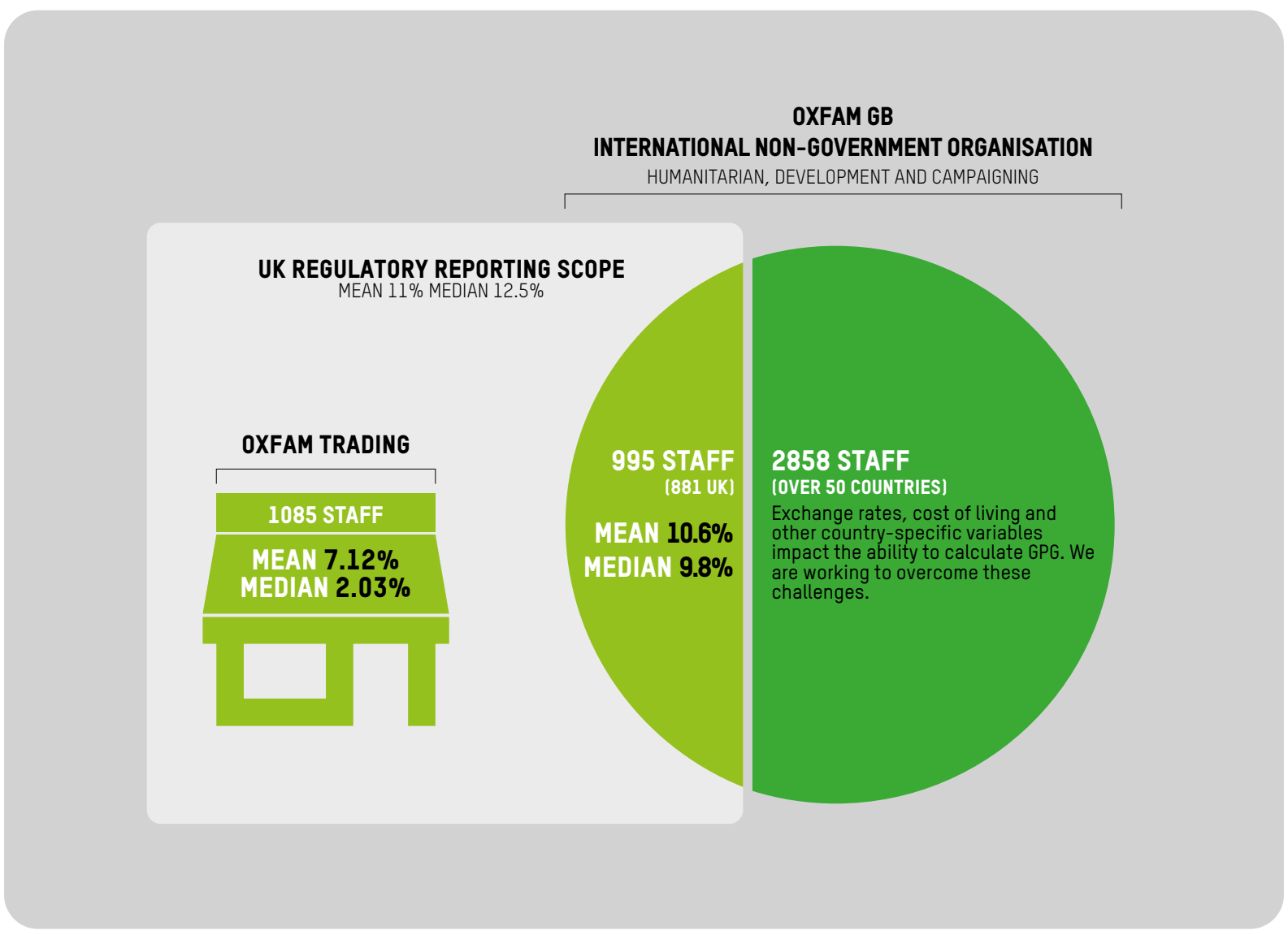

We are proud that in the UK, over $60 \%$ of our management roles are held by women, that we have twice the national average of women in information systems roles, twice the national average of men in part-time roles, and $84 \%$ of our staff reporting that their flexible working needs are met. However, there are areas where we must do better: for example, only $25 \%$ of our Leadership Team were women during the reporting period - this has increased to $37.5 \%$ over the past year; and we can also do more to promote diversity and inclusion beyond gender.

To move forwards as an organization, we have devised an analytical framework informed by the broader social and economic barriers which hold women back, including a context in which violence against women and girls must be recognized and challenged. The framework sets out four key areas against which Oxfam has shared analysis and is committed to make changes:

\begin{tabular}{|c|l|}
\hline 1 & LEADERSHIP \\
\hline 2 & UNPAID CARE WORK \\
\hline 3 & GENDERED ROLES \\
\hline 4 & SEXUAL HARASSMENT AND ABUSE \\
\hline
\end{tabular}

In this report, we share detailed information about our self-assessment in these four areas and how we intend to improve further, as part of our commitment to address our gender pay gap in a transparent way. 
The appalling sexual misconduct by former Oxfam staff in Haiti during 2011 highlights the need for ongoing change. We want to take this opportunity to reiterate how sorry we are for the shameful things that happened in our name. We are determined to do everything possible to put things right, and have developed a robust 10 -point action plan² to deliver on this commitment. The measures detailed in this report are some of the many ways we will do this.

To drive wider change, Oxfam's work on gender justice seeks to transform unequal gender and power relations and the structures, norms and values that underpin them. We believe this is critical to fighting poverty and inequality. This also includes looking at drivers other than gender: race, ethnicity, class, sexuality, gender identity, ability and age. But we also know that women, when they take control and take collective action, are the most important drivers of sustained improvements in women's rights. And they are a powerful force in beating poverty - not only for themselves, but for others too.

Mark Goldring, CEO, and Tina Proudlock, People Director, Oxfam GB. 


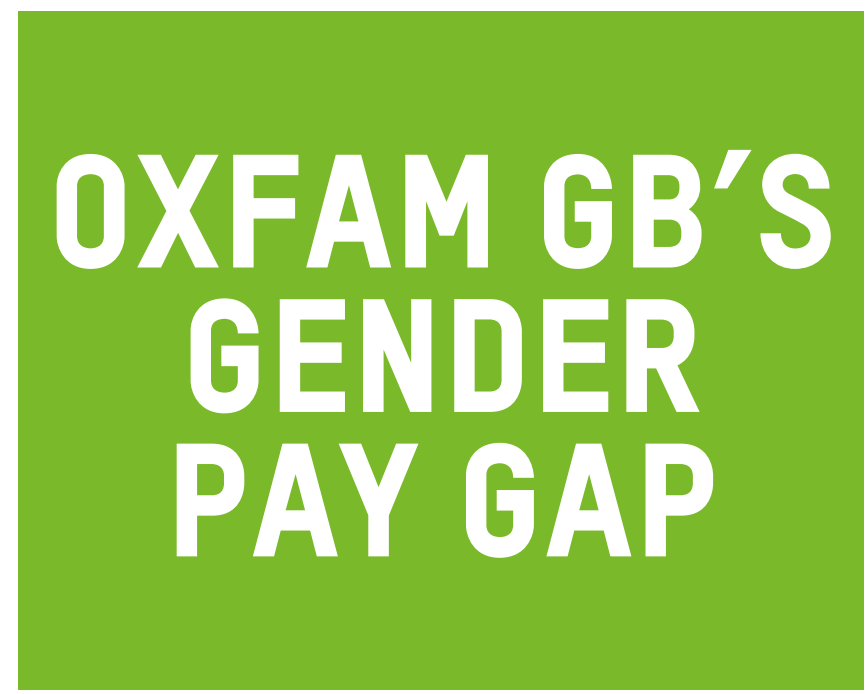

\section{$11 \%$ MEAN $12.5 \%$ MEDIAN}

OXFAM DOES NOT PAY BONUSES

As an organisation that is working to enable women to realise their rights, Oxfam GB is determined to build a fairer and more equal world for everyone - and, of course, this starts here, with us addressing our own gender pay gap.

\section{PROPORTION OF MEN AND WOMEN IN EACH PAY QUARTILE}
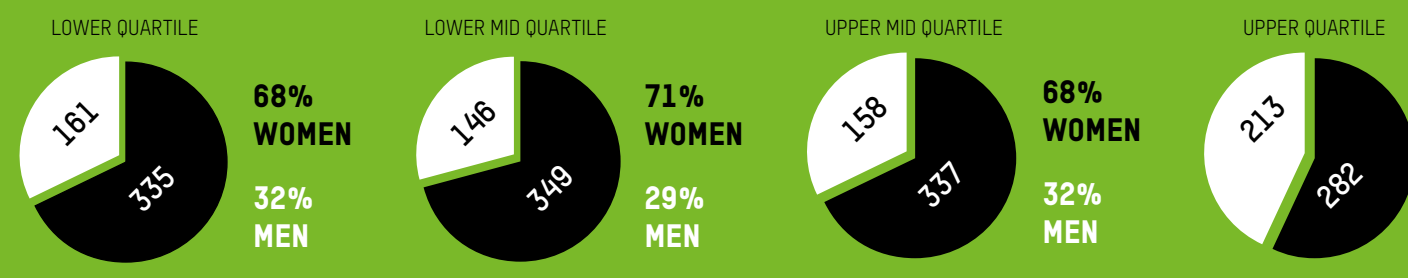

$57 \%$

WOMEN

$43 \%$

MEN

$\mathbf{8 4 \%}$ of staff state that Oxfam meets their flexible working needs
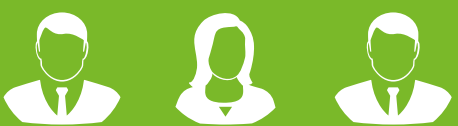

8
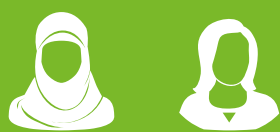

0
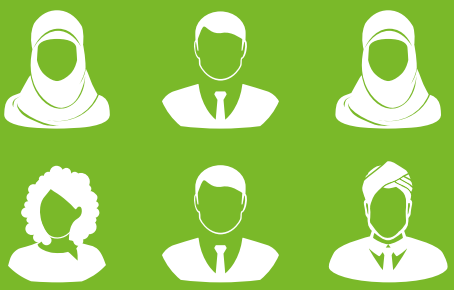

8
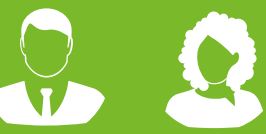

8
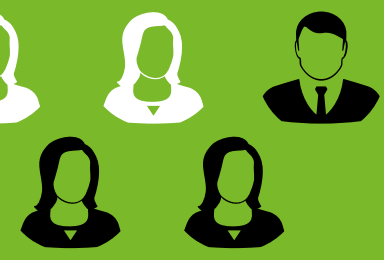
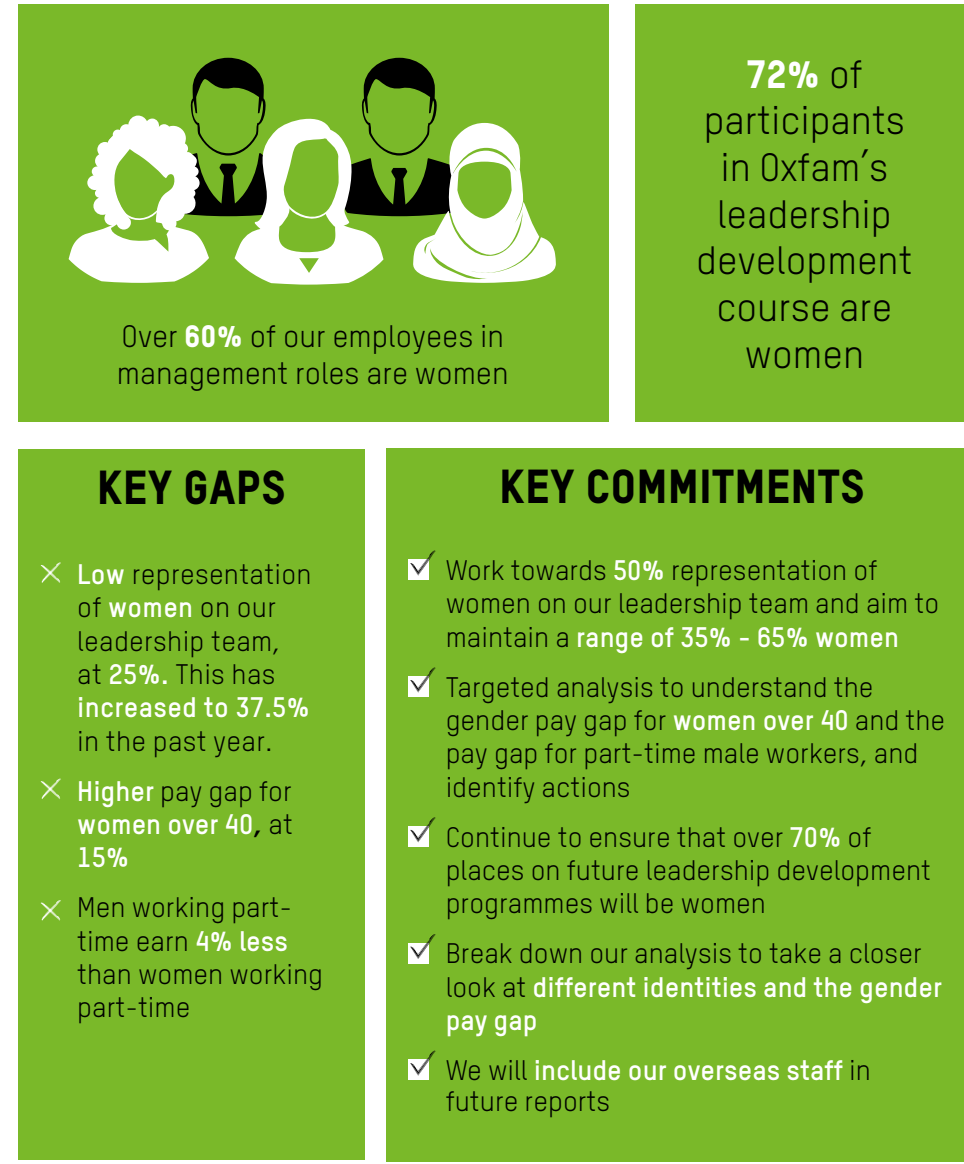

\section{KEY COMMITMENTS}

$\checkmark$ Work towards $50 \%$ representation of women on our leadership team and aim to maintain a range of $35 \%-65 \%$ women

$\checkmark$ Targeted analysis to understand the gender pay gap for women over 40 and the pay gap for part-time male workers, and identify actions

$\checkmark$ Continue to ensure that over $70 \%$ of places on future leadership development programmes will be women

$\checkmark$ Break down our analysis to take a closer look at different identities and the gender pay gap

$\checkmark$ We will include our overseas staff in future reports 


\section{UNDERSTANDING GENDER PAY GAPS AND THEIR DRIVERS}

To address gender pay gaps, it is important to understand what they represent, how they are different from equal pay, and to analyse the wider social trends that perpetuate them.

\subsection{THE GENDER PAY GAP: WHAT IS IT AND HOW DOES IT DIFFER FROM EQUAL PAY?}

The Equality and Human Rights Commission makes a clear distinction between the terms 'gender pay gap' and 'equal pay':

'Whilst both equal pay and the gender gap deal with the disparity of pay between women and men in the workplace, they are two different issues:

1. Equal pay means that men and women in the same employment performing equal work must receive equal pay, as set out in the Equality Act 2010.

2. The gender pay gap is a measure of the difference between men's and women's average earnings across an organisation or the labour market. It is expressed as a percentage of men's earnings.' 3

In Britain, the overall gender pay gap mean is $17.4 \%$, while the median is $18.4 \%{ }^{4}$

\section{What information are organizations required by law to report on and what do the terms mean?}

Organizations with more than 250 staff are required to publicly report on the following:

\begin{tabular}{|l|}
\hline REGULATORY REQUIREMENT \\
\hline Mean gender pay gap \\
\hline Median gender pay gap \\
\hline Mean bonus gender pay gap \\
\hline Median bonus gender pay gap \\
\hline Proportion of males receiving a bonus payment \\
\hline Proportion of females receiving a bonus payment \\
\hline Proportion of males and females in each quartile pay band \\
\hline A written statement, authorized by an appropriate senior person, which confirms the accuracy of their calculations \\
\hline
\end{tabular}

The 'mean' is the average salary. The 'mean gap' shows the percentage gap in the average salaries of men and women based on hourly rates of pay on 5 April this year.

The 'median' is the middle salary value when all the salaries are ranged from highest to lowest. The 'median gap' shows the percentage gap in median salaries (including bonus payments) of men and women based on standard hourly rates of pay on 5 April 2017. The median is more representative of typical pay differences than the mean because it is less affected by a handful of considerably higher (or lower) salaries. However, it ignores one of the most significant factors in determining a gender pay gap: the sometimes very high pay rates of largely male boardrooms.

'Quartiles' represent the percentage of women and men in four pay groups (from highest to lowest). 
The reporting criteria expose the differences in pay for women at different levels of an organization. However, taking action to narrow a gender pay gap solely based on the above ways of measuring it could inadvertently disadvantage women further - for example, reducing the number of women working in lower-level positions rather than increasing the number of women in senior positions.

To create sustained change, there is a need to understand and address the wider discriminatory social norms that cause and perpetuate gender pay gaps.

\subsection{WHAT ARE THE COMMON DRIVERS OF GENDER PAY GAPS?}

Gender pay gaps are a direct result of wider discriminatory social norms that prevent women from reaching higher earning job roles. As the Equality and Human Rights Commission explains, 'Although girls often do well at school, they tend to end up concentrated in employment sectors that offer narrower scope for financial reward whilst many of the highest paying sectors are disproportionately made up of male employees'. ${ }^{5}$

The causes of this situation are complex and often overlapping. Oxfam has developed a framework that sets out four priority areas to address gender pay gaps, to enable effective change within the workplace. This does not, however, preclude other areas in which women face discrimination and gender bias: the gender pay gap is also exacerbated by intersecting aspects of identity such as race, ethnicity, class, sexuality, gender identity, ability and age.

When recognizing and challenging the power imbalances experienced by women, it is very important to acknowledge that these are not the same for all women. Women of colour, disabled women, LGBTIQ+ women and women of different ability can all experience discrimination and exclusion based on the intersection of the different elements of their identity. Intersecting inequalities will therefore create a situation in which the gender pay gap needs to be understood alongside other 'gaps', such as the race gap. ${ }^{6}$

Oxfam is committed to do more work relating to the intersection of different identities and how these contribute to the gender pay gap. We are establishing a new working group on diversity which will take this forward and we will include further information on this in future reports. Taking action in each of the four areas below contributes to addressing some of the root causes of gender pay gaps. In section 2 we analyse what Oxfam is already doing, and what more we need to do, in each of these four areas.

\section{GENDERED LEADERSHIP}

The World Bank notes that: 'For women to push for reforms and for their voices to be transformative, they need to be heard where decisions are made - in parliaments, legal institutions, formal professional associations, governments, legally recognized labor movements, land boards, zoning and planning committees and the like.'7

Globally, it is still difficult for women to reach positions of leadership at any level, particularly if they are not part of a majority group - in the UK this still means being white and middle class or upper class. From national-level politics and senior levels of large corporations, to more local-level leadership such as in schools, hospitals and nongovernment organizations (NGOs), women still face discrimination and structural barriers based on gendered norms and assumptions. For example, women account for just $23 \%$ of parliamentarians globally and only $6.4 \%$ of chief executive officers (CEOs) in the world's 500 biggest corporations. ${ }^{9}$ This inequality is reflected in local governance too, where women comprise a small proportion of mayors and local councillors.

To drive wider change within organizations and companies, there is a need not only to encourage women into management/leadership positions by offering support and training, but also to develop and reflect norms of leadership that recognize and promote more diverse leadership styles and characteristics.

\section{UNPAID CARE WORK}

The gendered division of labour is at the root of workplace inequalities. An understanding of the broader gender inequalities which affect women's and men's experiences of the workplace must include recognition of unpaid care work, and policies to support the reduction and redistribution of this type of work.

There is no country in the world where women and men share unpaid care and domestic work equally. In the UK, women are four times more likely than men to give up paid work to do unpaid care work, the annual economic value of which is estimated to be $€ 77 \mathrm{bn} .{ }^{10}$

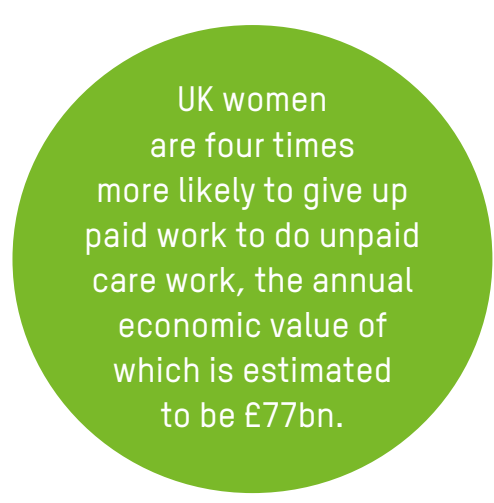


The disproportionate responsibility for unpaid care work (which includes but is not limited to caring for children, elderly people and people with disabilities) squeezes the amount of time that many women have for education and to earn a living. This impacts women's opportunity for professional development, promotion and increased earnings, and can impact mental health, as women juggle pressures at home, in the community, and at work.

Key steps in addressing gender pay gaps are to challenge the assumption that unpaid care work is primarily a woman's responsibility, and to provide a work environment that enables men and women to balance work and care responsibilities effectively.

\section{GENDERED JOBS AND WIDER SECTORAL TRENDS}

The roots of gender pay gaps can be traced to social norms and prejudices about gendered roles (what kind of work men should do, and what kind of work women should do) that begin at a young age. ${ }^{11}$ Gendered social norms consistently put greater value on types of work traditionally considered to be 'male' than on work traditionally considered 'female'; for example, roles that are considered to be 'caring' are more often seen as more appropriate for a woman than a man.

At the same time, women are often seen as less able to undertake roles that have traditionally been performed by men, which are often better paid. Whether due to active discrimination or unconscious bias, these attitudes have excluded many women from taking up highly paid and highly valued jobs, as well as from more senior roles in management and leadership. ${ }^{12}$

To drive broader change, there is a need to challenge assumptions that specific roles or sectors are male le.g. engineering or IT) and to actively support and encourage training, education and advancement of women in these roles and sectors.

\section{SEXUAL HARASSMENT AND ABUSE}

Sexual harassment, exploitation and abuse are all abuses of power. Women, men, girls and boys are all affected, and women and men can both be perpetrators. However, because women and girls are disproportionately affected by power imbalances, they are disproportionately affected by sexual abuse. Power imbalances experienced by lesbian, gay, bisexual, transgender and intersex (LGBTI) people and many other marginalized communities mean they are also at higher risk of abuse.

Most cases of sexual harassment and abuse are perpetrated by men against women and girls, and, by extension, a large portion of the burden of managing the consequences of it falls to women. As well as the trauma of experiencing sexual harassment or sexual abuse, staff subjected to these abuses of power often feel unable to report them, and may end up leaving their workplace altogether. Reporting or being witness to sexual misconduct can also involve long-term consequences to mental and physical health, and slow or even halt one's career progression.

To drive change there is a need for zero tolerance of sexism, sexual harassment and abuse in the workplace, with robust prevention mechanisms alongside trusted reporting and investigations. This will create workplaces where women can feel safe, respected and can thrive on an equal basis with men.

In the next section, we share detailed information about our self-assessment in the four areas mentioned above and how we intend to improve further, as part of our commitment to address our gender pay gap in a transparent way. 


\section{OXFAM GB'S GENDER PAY GAP}

This section includes both the results of the statutory analysis and the additional steps Oxfam has taken to identify and address root causes of the organization's gender pay gap. It provides an overview of Oxfam's organizational structure and how that impacts the pay gap. Finally, it sets out what Oxfam GB is already doing in the four key areas identified in the previous section:
1. Gendered leadership
2. Unpaid care work
3. Gendered jobs
4. Sexual harassment and abuse.

As of 5 April 2017 (as per statutory guidelines), Oxfam GB's gender pay gap was reported as follows.

\section{TABLE 1: OXFAM'S GENDER PAY GAP}

\begin{tabular}{|c|c|}
\hline REPORTING REQUIREMENT & OXFAM GB \\
\hline Mean gender pay gap & $11.03 \%$ \\
\hline Median gender pay gap & $12.5 \%$ \\
\hline Mean bonus gender pay gap & \multirow[t]{4}{*}{ Oxfam GB does not pay bonuses } \\
\hline Median bonus gender pay gap & \\
\hline Proportion of males receiving a bonus payment & \\
\hline Proportion of females receiving a bonus payment & \\
\hline Proportion of males and females in each quartile pay band & See Table 2 below \\
\hline
\end{tabular}

\section{TABLE 2: PROPORTION OF MALE AND FEMALE EMPLOYEES IN EACH QUARTILE PAY BAND}

\begin{tabular}{|l|l|l|l|l|l|l|l|l|}
\hline & \multicolumn{3}{|l}{ LOWER QUARTILE } & \multicolumn{2}{l|}{$\begin{array}{l}\text { LOWER MIDDLE } \\
\text { QUARTILE }\end{array}$} & \multicolumn{2}{l|}{$\begin{array}{l}\text { UPPER MIDDLE } \\
\text { QUARTILE }\end{array}$} & \multicolumn{2}{l|}{ UPPER QUARTILE } \\
\hline \multirow{2}{*}{ Oxfam GB } & Women & Men & Women & Men & Women & Men & Women & Men \\
\cline { 2 - 10 } & $68 \%$ & $32 \%$ & $71 \%$ & $29 \%$ & $68 \%$ & $32 \%$ & $57 \%$ & $43 \%$ \\
\hline Number of staff & 335 & 161 & 349 & 146 & 337 & 158 & 282 & 213 \\
\hline
\end{tabular}

Oxfam GB has on average 67\% women. Table 2 shows the percentage of women within each pay quartile.

Our equal pay audit from 2015 found an average difference in pay between men and women of less than $1 \%$ across our job grades. We will conduct another pay audit in 2018.

The following section aims to set out the key drivers and causes of Oxfam's gender pay gap. 


\subsection{OXFAM'S ORGANIZATIONAL STRUCTURE AND HOW IT RELATES TO THE GENDER PAY GAP}

Oxfam GB has two organizational models within it:

- An international NGO - a campaigning, development and humanitarian organization

- A retailer (Trading).

As separate operational models they have lower gender pay gaps, as evident in figure 1 and table 3.

\section{FIGURE 1: OXFAM GB'S TWO WORKING MODELS AND GENDER PAY GAP}

\section{OXFAM GB}

INTERNATIONAL NON-GOVERNMENT ORGANISATION

HUMANITARIAN, DEVELOPMENT AND CAMPAIGNING

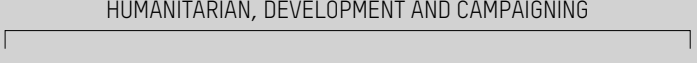

UK REGULATORY REPORTING SCOPE MEAN $11 \%$ MEDIAN $12.5 \%$

OXFAM TRADING

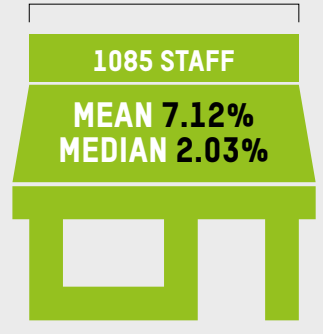

995 STAFF

(881 UK)

MEAN $10.6 \%$

MEDIAN $9.8 \%$

\section{STAFF}

(OVER 50 COUNTRIES)

Exchange rates, cost of living and

other country-specific variables

impact the ability to calculate GPG. We

are working to overcome these

challenges.

TABLE 3: OXFAM GB'S TWO ORGANIZATIONAL MODELS OF TRADING AND AN INTERNATIONAL NGO

\begin{tabular}{|l|l|l|l|l|}
\hline EMPLOYEE GROUPING & $\begin{array}{l}\text { OXFAM GB AS PER } \\
\text { STATUTORY GUIDANCE }\end{array}$ & $\begin{array}{l}\text { INTERNATIONAL NGO } \\
\text { STAFF }\end{array}$ & $\begin{array}{l}\text { INTERNATIONAL NGO } \\
\text { STAFF IN STATUTORY } \\
\text { REPORTING }\end{array}$ & $\begin{array}{l}\text { TRADING: ALL ARE } \\
\text { INCLUDED IN } \\
\text { STATUTORY } \\
\text { REPORTING }\end{array}$ \\
\hline Number of employees & $\begin{array}{l}2,024 \text { UK and } 56 \\
\text { international }\end{array}$ & $\begin{array}{l}939 \text { UK and 2914 } \\
\text { international }\end{array}$ & $\begin{array}{l}995 \text { lof which } 56 \text { are } \\
\text { non-UK) }\end{array}$ & 1085 \\
\hline Mean & $11 \%$ & $\begin{array}{l}\text { We are working on } \\
\text { the challenges } \\
\text { outlined in Figure } 1 \\
\text { to measure this. }\end{array}$ & $10.6 \%$ & $7.12 \%$ \\
\cline { 4 - 5 } & $12.5 \%$ & $9.8 \%$ & $2.03 \%$ \\
\hline
\end{tabular}




\section{Oxfam GB - international non-government organization (INGO)}

The non-UK-based contracts that are included in the statutory reporting ${ }^{13}$ scope is a very small group of 56 contracts which are not representative of the 2914 0xfam GB non-UK-based contracts. Of the 56 contracts, we confirm that $50 \%$ were held by women, with representation from 50-52\% women per grade/level within the reporting scope.

While not all international employees fall under the gender pay gap reporting requirements for the UK, Oxfam GB is committed to transparent reporting on gender pay, irrespective of where our employees are based. However, collecting data on the additional non-UK-based contracts is complex for the following reasons:

- On 5 April 2017, the above-mentioned 56 international contracts were issued by Oxfam GB, which managed pay structures and recruitment. However, starting from April 2017, line management for Oxfam GB non-UK staff has started to transfer to Oxfam International (0I). This arrangement is a key step in uniting the affiliates under a single 'One Oxfam' structure. ${ }^{14}$

- Currently Oxfam GB does not have centralized pay details required to report our gender pay gap for all our non-UKbased staff who work in more than 50 countries. If centralized, the pay gap analysis would be skewed by exchange rates, cost of living and other country-specific variables.

Despite these constraints, we are working with Oxfam International to agree appropriate steps to develop a full picture.

\section{OUR COMMITMENT TO REPORT ON OUR INTERNATIONAL STAFF}

- We will report on all Oxfam GB overseas staff by grade and gender in Oxfam's next UK gender pay gap report, while clearly stating the limitations in the reported data.

- We will analyse the gender pay gap for our Oxfam GB overseas employees by the end of 2019 as part of our annual pay review support for those countries.

Given the lack of international staff data, the following analysis will be based on UK staff only.

\section{OXFAM GB TRADING}

Figure 2 illustrates the difference between the INGO staff (UK) and Trading. It shows the proportion of men and women at each grade, and the blue outlines at each level indicate which proportion of staff are within our Trading operational model, which, with approximately 650 shops, has a much higher proportion of lower grade roles. This helps to explain how the Trading gender pay gap differs from the INGO gender pay gap as shown in table 3. 


\section{FIGURE 2: OXFAM GB UK STAFF BY GRADE AND GENDER, HIGHLIGHTING THE TWO} ORGANIZATIONAL MODELS BY LEVEL (BLACK BOXES INDICATE TRADING ROLES)

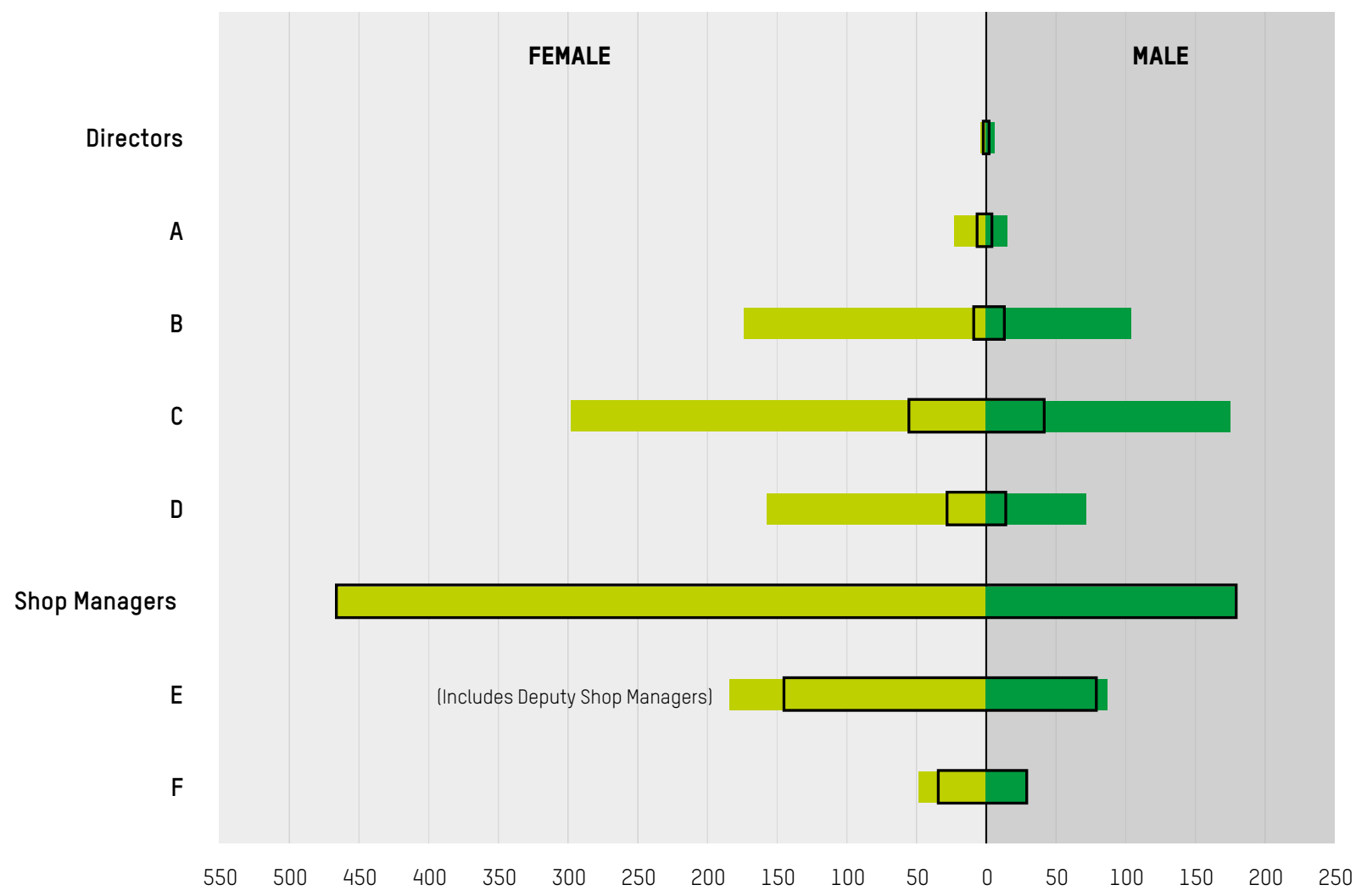

While the two organizational models help to explain our gender pay gap, the following sections will look at all UK staff as one group, except for section 2.4.1 - gendered roles - which looks at retail.

To identify how best to address Oxfam GB's gender pay gap, we have undertaken an analysis of what the organization is already doing in each of the four areas outlined in section 1.2. Our aim is to be transparent about our self-assessment and our commitments.

Due to the complexities regarding data for overseas contracts, as already noted, the following analysis will focus on UK-based employees only. 


\subsection{LEADERSHIP IN THE WORKPLACE}

On 5 April 2017, Oxfam's Leadership Team of 8 staff comprised 6 men and 2 women (25 percent). Over the past year, representation of women has increased to $37.5 \%$. Oxfam GB has committed to continuing to improve the gender balance of its Leadership Team.

\section{Our commitment to increase representation of women in Oxfam leadership roles}

To address the low representation of women at director level, the Leadership Team has committed to taking the following actions:

- Working towards 50:50 representation, with an aim to maintain the range of $35 \%$ to $65 \%$ women. When recruiting for new Leadership Team roles, we commit to having shortlists with at least $50 \%$ of women.

- Reviewing the steps we need to take to ensure that Leadership Team roles (and also more roles at senior levell are designed in such a way that they are more likely to attract women.

- Ensuring at least 70\% female participation in our leadership development programmes.

- Continuing to embed Oxfam GB's feminist leadership model through all our leadership development work, including specific sessions with the Leadership Team and a Senior Gender Leadership programme to target senior staff.

Oxfam GB has on average 67\% women. Other than at director level, Oxfam GB consistently has more than 60\% representation of women in senior grades.

\section{TABLE 4: PERCENTAGE AND NUMBER OF WOMEN AT EACH LEVEL (UK ONLY)}

\begin{tabular}{|l|l|l|l|}
\hline JOB GRADE & $\%$ OF WOMEN & $\begin{array}{l}\text { TOTAL } \\
\text { NUMBER OF } \\
\text { WOMEN }\end{array}$ & COMMENTS \\
\hline Directors & $25 \%$ & 2 & CEO is male \\
\hline A & $61 \%$ & 22 & Senior managers \\
\hline B & $63 \%$ & 175 & Managers \\
\hline C & $63 \%$ & 299 & Professional job grade \\
\hline D & $69 \%$ & 158 & Semi-professional job grade \\
\hline Shop managers & $72 \%$ & 468 & \\
\hline E & $67 \%$ & 185 & Administrative job grade, includes all deputy shop managers \\
\hline F & $62 \%$ & 47 & Majority warehouse staff \\
\hline
\end{tabular}

Oxfam's senior management team (SMT) - i.e. all direct line reports to directors and our Internal Communications lead - is $66 \%$ female, and therefore consistent with the average representation of women in Oxfam GB working in the UK. Most women on the SMT are on grade A.

\section{What is Oxfam doing to improve women's representation in leadership roles?}

Aware that we have low representation of women in our Leadership Team (director level), we have taken steps to enable the advancement of women past middle management. Oxfam GB is aware of the impact that caring responsibilities can have on career advancement (see section 2.3 Unpaid care work),

Oxfam's leadership approach is rooted in feminist leadership thinking. ${ }^{15}$ However, we haven't yet sufficiently embedded this into our culture and ways of working, and this is an area we are working to improve; for example, by including a strong emphasis on self, power dynamics, and our values of inclusiveness, empowerment and accountability in our core leadership development offer, and in related work such as recruitment. For example, our leadership practices constitute our competency model which shapes our job roles and recruitment criteria. 


\section{BOX 1: OXFAM GB'S GENDER LEADERSHIP PROGRAMME}

This programme is designed for men and women who want to explore their personal attitudes and beliefs about gender. It aims to develop participants' understanding and knowledge of gender justice and women's rights, which better enables them to advocate, champion or lead in their sphere of influence, applying those principles to their work and home life.

More than 150 people (including men) have participated in this programme, which started in 2015. Further courses, including one for senior staff (those in A and B grades), have begun in 2018 . We will continue to encourage men to take part, via our male and female alumni community and more widely. We will start monitoring the gender balance on the course and publish gender-disaggregated data on participants for subsequent years.

\section{Our commitment to support the promotion of women into senior positions}

- We will continue our Gender Leadership programme, encouraging men and women to take part.

- We will continue to include content covering issues such as bias, assumptions, diversity and inclusion in our development offer.

- We will provide resources on CV and interview preparation for all staff, and specific resources for women to support them with career progression.

- In Trading, there are several management development activities planned for 2018/19 - for all middle and senior managers, including refresher training around accountability for managing people and managing risk. Training materials and content will be reviewed to ensure that they address gender and diversity.

\section{BOX 2: WOMEN'S LEADERSHIP NETWORK}

The Women's Leadership Network is an employee-led initiative, which was started by staff in April 2015. It emerged out of a sense that the organization could do more to inspire and enable women within Oxfam House to fulfil their potential. The network runs a variety of activities, from providing a space for reflection and learning on women's leadership, to a women's mentoring programme. It aims to influence Oxfam's culture to be more supportive for women's leadership, growth and development.

The Women's Leadership Network is planning further work in 4 key areas:

- Sexist language and behaviour: supporting everyone to challenge it.

- Flexible working: support to managers and individuals, as well as contributing to changes in the wider culture around workload and further openness to flexibility.

- Connecting and supporting each other: via mentoring, champions and work around self-care.

- Leadership: actions, specific talks on diverse leadership styles and inputs into organizational work around leadership development and the Gender Leadership programme.

The network will be supported by Oxfam in all these areas. 


\subsubsection{RECRUITMENT AND GENDER BIAS IN THE WORKPLACE}

We have analysed the starting salary rates for men and women employees of Oxfam GB. More than half of our UK-based staff (54\%) start a role above the minimum pay band (52\% of women and $57 \%$ of men). Initial analysis in 2017 and results from our most recent equal pay audit in 2014/15 suggest that sensitivity to wider market value placed on roles and gendered jobs contributes to this difference. Our 2018 equal pay audit will investigate the reasons for this difference in more detail.

\section{What Oxfam is doing already to address gender bias in recruitment}

Oxfam GB has a Recruitment and Equal Opportunities policy, which, along with related training courses, aims to influence and promote equality.

We run a mandatory training course on recruitment and selection for all new managers whose role includes recruitment, with a refresher course every three years.

The course aims to equip managers with specific skills - for example, on how to write non-discriminatory adverts and how to be aware of unconscious bias throughout the selection process. It also explores how to make selection decisions that value the full range of skills and attributes an individual will need to help achieve Oxfam's development aims. The course includes a session on diversity, inclusion and bias - areas that are explored in more depth in our compulsory Managing People in Oxfam training for managers and our Leadership Paths programme for aspiring senior leaders. We also encourage managers to offer flexible working modalities from the advertising stage, and use the Happy to Talk flexible working logo on all our adverts. For more information on flexible working at 0xfam, see section 2.3.2.

\section{Our commitment to address gender bias in recruitment}

To understand where we can focus our efforts in future, we will:

- track how many roles are advertised as potential part-time roles, job shares and/or offering flexible hours;

- ensure that all newly recruited managers have undergone mandatory recruitment training as soon as possible;

- track starting pay for men and women.

Steps to address recruitment directly:

- We will implement a pilot to align our recruitment for senior leadership positions with our leadership approach, with a strong diversity and inclusion focus. This should yield further learning for our wider recruitment processes.

- We will incorporate flexible working into our recruitment training.

\subsection{UNPAID CARE WORK}

Oxfam supports flexible working and supports staff with care responsibilities in current work and future commitments, as outlined below.

\subsubsection{MATERNITY, PATERNITY AND ADOPTION LEAVE}

\section{What is Oxfam doing to improve provision?}

Oxfam GB pays enhanced maternity and adoption leave pay. It also encourages shared parental leave and will be introducing enhanced shared parental leave pay (for partners) from April 2018.

There is an on-site nursery at Oxfam headquarters (Oxfam House), where more than 800 of our UK staff are based. It is run on a not for profit basis and gives employees a convenient option for nursery-based childcare. It has been in place for almost 30 years. 


\section{Our commitment to improve provision for maternity, paternity and adoption leave}

To understand where we can focus our efforts in future, we will:

- collect and analyse data on the number of staff taking maternity, paternity and adoption leave;

- analyse recent data and gather further qualitative data on men and women returning to work after maternity, paternity and adoption leave, and use this data to inform how we shape our support offer for parents before they take leave and after they return from leave;

Steps to address maternity, paternity and adoption leave directly:

- We will design and deliver a communication strategy to ensure that employees are aware of what support is available and how to access it.

- We will introduce enhanced shared parental leave pay from April 2018, to encourage and support more men to take time out for childcare responsibilities.

\subsubsection{ENABLING MORE PART-TIME WORK, JOB SHARES AND FLEXIBILITY}

Across Oxfam's UK-based staff, 38\% of roles are part-time; the gender breakdown shows that $44.3 \%$ of our female employees and $25.6 \%$ of our male employees are in part-time roles. These are both higher than the national average for part-time workers ( $41 \%$ for women and $12 \%$ for men). ${ }^{16}$

While the percentage of men working part-time at 0xfam is more than twice the national average, women working part-time are paid more (on average) than men working part-time, which has resulted in a 'negative' gender pay gap of $-4.1 \% .{ }^{17}$ The difference in pay is lower than the national average of $5.1 \%$. Initial analysis suggests that this is a result of proportionately more men working part-time at junior levels, which are not on a par with women at senior levels. To understand this further, we have collected data on the percentage of roles in each grade that are part-time.

$84 \%$ of staff reported that Oxfam is already meeting their flexible

working needs.

Staff survey 2016

\section{TABLE 5: PERCENTAGE OF PART-TIME ROLES PER GRADE AND BY GENDER}

\begin{tabular}{|l|l|l|l|}
\hline Grade & $\begin{array}{l}\% \text { of jobs which are } \\
\text { part-time (UK) }\end{array}$ & $\begin{array}{l}\% \text { of jobs which are } \\
\text { part-time and filled by } \\
\text { women (UK) }\end{array}$ & $\begin{array}{l}\% \text { of job which are } \\
\text { part-time and filled by } \\
\text { men (UK) }\end{array}$ \\
\hline Director & $0 \%$ & $0 \%$ & $0 \%$ \\
\hline A & $17 \%$ & $14 \%$ & $3 \%$ \\
\hline B & $23 \%$ & $19 \%$ & $4 \%$ \\
\hline C & $21 \%$ & $19 \%$ & $3 \%$ \\
\hline D & $21 \%$ & $18 \%$ & $3 \%$ \\
\hline $1 *$ & $16 \%$ & $16 \%$ & $0 \%$ \\
\hline 1 & $15 \%$ & $11 \%$ & $4 \%$ \\
\hline 2 & $63 \%$ & $45 \%$ & $17 \%$ \\
\hline 3 & $92 \%$ & $71 \%$ & $21 \%$ \\
\hline E & $67 \%$ & $52 \%$ & $15 \%$ \\
\hline F & $29 \%$ & $24 \%$ & $5 \%$ \\
\hline Part-time total & $38 \%$ & $30 \%$ & $8 \%$ \\
\hline
\end{tabular}

Oxfam GB has gender pay gap of $12.7 \%$ (median) for full-time staff, which is higher than the national median of $9.1 \%{ }^{18}$ This is due to the higher representation of women working in our shops and in lower grade jobs, and the lower representation of women in our leadership team. There may be a relationship with the proportionality of men and women working part-time vs. full-time. Please see our commitments regarding increasing the representation of women in our leadership team (section 2.2), for new data analysis for full- and part-time staff later in this section, and our commitment to understand the high proportion of women in our shops (section 2.4.1). 


\section{What is Oxfam doing to promote part-time working, job shares and other flexible working?}

As part of our aim to recruit and retain a diverse workforce, Oxfam GB has a favourable attitude to various flexible working options, as reflected in our Flexible Working Policy. This includes flexibility for people in office-based roles to work from home, and office core hours of $10 \mathrm{am}$ till 4pm, around which people can flex their start and leave times.

All roles are advertised with the Happy to Talk flexible working logo, both to encourage applications from candidates seeking flexible working arrangements and conversations on flexible working with the recruiting manager at interview stage.

We monitor staff satisfaction with our flexible working offer through the annual staff survey. In $2016,84 \%$ of staff reported that Oxfam is already meeting their flexible working needs.

We have an online flexible working community where we share flexible working opportunities internally. We regularly share content on flexible working in our Managers' Bulletin, to ensure that all managers know of any developments in flexible working arrangements and to offer practical tips and share successful ideas with all managers.

We have successful examples of senior job shares between women at senior level and want to sustain and make them more visible.

\section{Our commitment to improve our flexible working offer}

To understand where we can focus our efforts in future, we will:

- analyse data on extra hours worked for full-time and part-time staff, by grade and gender, through an annual staff survey;

- seek to understand and address the negative pay gap for part-time men with the aim to encourage more men to work part-time if they wish to;

- analyse promotions between grades for part-time versus full-time staff, by gender;

- collate and analyse data on how Oxfam staff use flexible working, and if and how requests are being refused, through an annual staff survey;

- analyse flexible working for women and men on fixed-term contracts compared with open-ended contracts via an annual staff survey;

- use the above analyses to disaggregate data for women over 40 to help us understand the significant pay gap for this group.

Steps to further support our flexible work culture:

- We will develop additional resources on flexible working for all staff and put these on our intranet. This will include top tips for flexible working, short stories and resources, and a guide to job-sharing. These will also be directly linked into our Flexible Working Policy so that those employees exploring flexible working options can see positive examples and success stories. We will continue regular communications for managers and staff on our commitment to support flexible working.

\subsubsection{WOMEN AGED OVER 40}

The pay gap within Oxfam GB in the UK for women aged over 40 , compared with men over 40 , is $15.6 \% .{ }^{19}$ This is considerably higher than the Oxfam GB UK staff mean of $9.87 \%$ and reflects a similar trend identified by the Office for National Statistics (ONS) for the United Kingdom..$^{20}$ The pay gap for women under 40 relative to men, however, is $-2.16 \%$.

Almost a third (31\%) of Oxfam's women employees aged 40 and over are in professional job grades ${ }^{21}$ or above (see Table 6), compared with $46 \%$ of men aged 40 and over. Forty-five percent of women aged 40 and over are working in Oxfam's shops, compared with $33 \%$ of the men who are over 40. 


\section{TABLE 6: ROLES HELD BY OVER 40S, BY GENDER}

\begin{tabular}{|l|l|l|l|l|}
\cline { 3 - 4 } \multicolumn{2}{c|}{} & \multicolumn{2}{l}{$\%$ of jobs by grade, held by people over 40} & \multirow{2}{*}{ Women } \\
\hline $\begin{array}{l}\text { Oxfam GB's UK staff } \\
\text { aged over } 40 \text { years }\end{array}$ & $\begin{array}{l}\text { Number of roles } \\
\text { held by people over } \\
40 \text { years }\end{array}$ & Women and men & Men & 75\% \\
\hline Director & 8 & $100 \%$ & $33 \%$ & $25 \%$ \\
\hline Grade A & 33 & $92 \%$ & $23 \%$ & $58 \%$ \\
\hline Grade B & 161 & $58 \%$ & $21 \%$ & $35 \%$ \\
\hline Grade C & 234 & $49 \%$ & $10 \%$ & $28 \%$ \\
\hline Grade D & 85 & $37 \%$ & $20 \%$ & $27 \%$ \\
\hline $1^{*}$ & 54 & $72 \%$ & $22 \%$ & $99 \%$ \\
\hline 1 & 104 & $75 \%$ & $20 \%$ & $28 \%$ \\
\hline 2 & 235 & $79 \%$ & $17 \%$ & $58 \%$ \\
\hline 3 & 99 & $74 \%$ & $16 \%$ & $58 \%$ \\
\hline Grade E & 149 & $54 \%$ & $18 \%$ & $39 \%$ \\
\hline Grade F & 48 & $63 \%$ & & $45 \%$ \\
\hline TOTAL & 1,210 & & \\
\hline
\end{tabular}

\section{Our commitment to support women employees aged 40 and over}

Flexible working is one of the key areas through which we can support women over 40 , who often have care responsibilities - a major factor in slowing down their career progression compared with men. See the commitments in the previous section 2.3.2 for details of the actions we will take to address this pay gap.

\subsubsection{MENTAL HEALTH AND SELF-CARE}

Aware that juggling work and unpaid care can have an impact on mental health, Oxfam recognizes that supporting women's and men's mental health in the workplace can enable both to balance unpaid care with their work for Oxfam more successfully. This will help women to progress and succeed at work, and support men who take on more unpaid care work - and by extension address the gender pay gap.

Recognizing the importance of mental health at work requires an approach to both management and workplace culture that is prepared to challenge the division between employees' work and private lives (and health), and broader taboos around mental health. The pressures of working for an organization such as Oxfam, in which people are committed to a broader set of issues and causes, can often place undue stress on employees (for example, due to working beyond the contracted hours). It can also create feelings of isolation and lack of confidence in individuals who are struggling to manage heavy workloads.

\section{What is Oxfam doing to address workload and other pressures?}

Workload emerged as an area of concern in our 2016 staff survey results, with the following actions implemented in response.

- The Trading team hired 187 deputy shop managers to reduce workload for shop managers.

- The Leadership Team reduced the number of corporate objectives (from 9 to 6), encouraging teams, managers and individuals to do the same, and clearly linking those objectives to our vision.

-Within our organizational change programme, which is helping to deliver the vision, we established a project management unit to provide visibility for all major change projects, and to improve support for staff delivering change and business as usual. 
Despite these measures, the 2017 staff survey results showed that staff are still struggling with workload. To address this, each team, together with their director, will explore the results in more detail to understand what is driving workload concerns in their area.

All Oxfam employees have access to confidential counselling services, which provide support for work and personal issues. We hold events at least once a year around mental health and publicize the support available for staff.

We also have a network of mental health first aiders in our headquarters in Oxford. In Trading, all the Human Resources (HR) advisors have been trained for this role, and have since provided training for shop managers at their respective area meetings around the country. This training is now provided on an as-needed basis.

\section{Our commitment to supporting employees' mental health and self-care}

-We will implement training for 16 of our HR Business Partners, who directly support line managers in mental health first aid, by March 2018, in collaboration with Mind.

- We will continue to run our resilience webinar, which covers self-care and how to support others. It is accessible to all staff. Resilience will continue to be part of our leadership development offer.

\subsection{GENDERED JOBS AND WIDER SECTORAL TRENDS}

Within society, active or unconscious bias has resulted in lower pay for job roles traditionally occupied by women, and women being under-represented in higher paid roles traditionally occupied by men. For example, science and IT have been predominantly held by men and administrative and caring roles have predominantly been held by women.

The charity sector within the UK has a higher proportion of women employees than men. This is reflected in Oxfam GB's UK-based job roles, which have an average representation of $67 \%$ women.

One hypothesis for this is that women are attracted to the charity sector as it reinforces broader social norms that ascribe caring roles (in the family or community) to women. ${ }^{22}$ As Oxfam advocates for gender justice, it can also be argued that a higher proportion of women working for Oxfam is representative and appropriate.

In seeking consistent cross-organizational representation of women for Oxfam GB, we benchmark against Oxfam GB's average number of women (67\%) as well as an equal balance of men and women (50\%). Even with that adjustment, we see wider sectoral trends within three key areas of the organization: Trading (retail), Information Systems, and administrative roles.

\section{TABLE 7: REPRESENTATION OF WOMEN IN INFORMATION SYSTEMS, TRADING SHOPS AND ADMINISTRATIVE ROLES}

\begin{tabular}{|l|l|l|l|l|}
\hline ROLE & $\begin{array}{l}\text { NATIONAL AVERAGE } \\
\text { (ONS) }\end{array}$ & CHARITY SECTOR & $\begin{array}{l}\text { OXFAM GB \% ROLES } \\
\text { FILLED BY WOMEN }\end{array}$ & $\begin{array}{l}\% \text { OF OXFAM GB UK } \\
\text { STAFF (MALE AND } \\
\text { FEMALE) IN ROLES }\end{array}$ \\
\hline $\begin{array}{l}\text { Information } \\
\text { Systems }\end{array}$ & $17 \%^{23}$ & N/A & $43 \%$ & $5 \%$ \\
\hline $\begin{array}{l}\text { Shop staff (within } \\
\text { Trading) }\end{array}$ & $43 \%^{24}$ & $78 \%^{25}$ & $72 \%$ & $41 \%$ \\
\hline Administration & N/A & N/A & $67 \%$ & $13 \%$ \\
\hline
\end{tabular}

With approximately 650 shops, Oxfam has significantly more employees in shop roles than in any of our other UKbased operations ( $41 \%$ ) (see table 7). While our pay for shop roles is above the charity sector average, the pay band sits within the lower half of Oxfam's structure. With $72 \%$ women in these roles - which equates to almost half of Oxfam's UK staff - our overall organizational pay gap figure is significantly affected.

We now look at the data on these three areas (Trading, Information Systems and administrative roles) in more detail, before outlining what Oxfam is doing to address the pay gap, and our commitment for the future. 


\subsubsection{TRADING ROLES}

When Trading is analysed as a single business model, it has a lower gender pay gap, with a mean of $7.12 \%$ and median of $2.03 \%$.

Oxfam's shop teams comprise volunteers and paid shop managers and deputy managers. There are 835 paid shop managers and deputies, of whom 598 are female and 237 are male, with women comprising $67.6 \%$ of staff in the Trading division. Women account for $72 \%$ of shop staff - a figure that is lower than our benchmark for female representation for shop managers compared with other charities. Women's representation at senior management level is consistent with the average number of women in Oxfam GB, which is 67\%. Oxfam's Trading division has made changes to increase the representation of women at its leadership level. Women now comprise $66 \%$ of the Trading Leadership Team: there are six roles, including the Trading director, four of which are filled by women at grade $A$, one male at grade $A$, and one male director. The current composition has been planned for and developed over the past 12 months. Of the six trading leadership team members, four are participating in Oxfam's Leadership Paths development programme (see section 2.2.) for more information.

\section{Our commitment for future action on Trading roles}

- We are committed to understanding why our volunteering and shop roles attract more women than men, and withhold judgement about whether this should give cause for concern until we know more.

\subsubsection{INFORMATION SYSTEMS}

Information systems is an area of the economy that reflects the stereotypical gendered division of roles. As with engineering, it is seen to be 'technical', and thus an area in which skills are very highly valued, and employees are predominantly male.

With $43 \%$ of women employees in information systems roles, Oxfam GB has more than twice the national average (17\%) for women working in this area. The head of the Information Systems department, our Chief Information Officer (CIO), is a woman who progressed to this role from within the organization. She is also part of the cohort of our Leadership Paths programme for aspiring senior leaders, of whom $72 \%$ of participants are women.

\section{TABLE 8: MEAN, MEDIAN AND REPRESENTATION OF WOMEN IN OXFAM GB'S INFORMATION SYSTEMS ROLES}

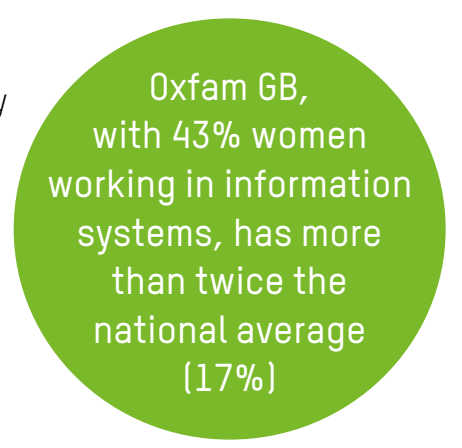

\begin{tabular}{|l|l|l|l|l|l|}
\hline ROLE & $\begin{array}{l}\text { NATIONAL } \\
\text { AVERAGE (ONS) }\end{array}$ & $\begin{array}{l}\text { OXFAM GB \% OF } \\
\text { WOMEN }\end{array}$ & $\begin{array}{l}\text { NUMBER OF } \\
\text { EMPLOYEES IN } \\
\text { INFORMATION } \\
\text { SYSTEMS ROLES }\end{array}$ & $\begin{array}{l}\text { INFORMATION } \\
\text { SYSTEMS MEAN } \\
\text { PAY GAP }\end{array}$ & $\begin{array}{l}\text { INFORMATION } \\
\text { SYSTEMS } \\
\text { MEDIAN PAY GAP }\end{array}$ \\
\hline Information Systems & $17 \%$ & $43 \%$ & 101 & $4.4 \%$ & $10 \%$ \\
\hline
\end{tabular}

\section{What is 0xfam doing to increase representation of women in information systems roles?}

Our Information Systems team has built a commitment to diversity and inclusion within their management team and in their global operating models. Senior managers are held to account to meet diversity objectives through the performance management process. All new starters in the team are strongly encouraged to undertake a diversity course.

Overall, the technology sector is still struggling to advance gender equality; in Oxfam's Information Systems department, we are proud of our track record in promoting gender equality. In the past, the team has spearheaded community networking events for experienced professionals looking for flexible working options. Our ClO has recruited to her own team from such events. 


\section{Our commitment to improving women's representation in the Information Systems department}

- We will continue working to drive awareness and influencing around gender equality.

\subsubsection{ADMINISTRATIVE ROLES}

Across sectors, administrative roles have traditionally been occupied by women as a legacy of the days when women were mainly restricted to taking up secretarial roles. These roles often involve fixed hours and can be part-time, which appeals to many women who continue to be responsible for most of the unpaid care work in families and communities (see section 2.3). Within Oxfam GB, two-thirds (67\%) of roles in the administrative job grade are filled by women. This is consistent with the average percentage of women in Oxfam GB as a whole.

\section{Our commitment to helping more women move out of administrative roles}

- We will collect and analyse data on promotions from within the administrative level and use this analysis to inform next steps.

\subsection{SEXUAL HARASSMENT AND ABUSE}

\section{What Oxfam has done to date to address sexual harassment and abuse}

Oxfam is an organization which rejects discrimination and fights for justice, including gender justice. If an individual engages in sexual harassment, sexual exploitation or sexual abuse of others, this represents a gross violation of Oxfam's purpose as well as its code of conduct, signed by every employee.

Oxfam is committed to minimizing the risk of sexual harassment, exploitation and abuse in our organization. This means that we will do everything in our power to prevent it from happening; and if it does happen, we will take the necessary action to root it out. We have made significant improvements since we uncovered sexual abuse by former staff in Haiti in 2011, including creating a dedicated safeguarding team to tackle and prevent abuse, and introducing a confidential whistle-blowing hotline.

The Safeguarding Team's work has included:

- delivering training and awareness raising sessions (prevention) to staff, volunteers, and partners;

- receiving complaints and disclosure of sexual abuse and exploitation;

- investigating allegations of sexual misconduct, including sexual abuse, sexual exploitation, and sexual harassment;

- developing policies and procedures;

- providing support to staff, volunteers, and others affected by these issues;

- supporting programmes to mainstream and design safer programmes;

- developing and supporting an international network of Safeguarding Focal Points;

- supporting leadership to invest in safeguarding mechanisms, and risk prevention and management.

We believe that the rise in allegations since 2012 is a result of more people being aware of our safeguarding and whistle-blowing procedures and having more confidence to report incidents.

But we acknowledge that this is a learning process for all of us within the organization and that we can and should do more. We need to continue to act to change the organizational culture within Oxfam and more broadly, across the aid and development sector, to tackle any form of harassment, exploitation, discrimination or abuse. 


\section{Our commitment to strengthen our work on sexual harassment and abuse in the workplace}

We are committed to fixing the things we got wrong so that we can better protect the people we serve - and continue to fight poverty wherever and however it exists.

Our commitments have been agreed by the Oxfam Leadership Team. We will follow this plan and continue to listen and learn to ensure a comprehensive and accountable response from Oxfam around the world, which will lead to deep-rooted and lasting change.

We want to make significant and necessary changes to our policy, practice and culture to help stamp out exploitation, abuse and harassment from all parts of our confederation - protecting those we work with and ensuring justice for survivors of abuse. We want to ensure that when it occurs - as it does in all sectors - we have the systems and organizational culture in place to ensure that justice is done.

Our actions focus on:

- demonstrating a meaningful commitment to transparency and accountability, including through the establishment of an independent commission to review our past and current work - the findings of which will be public, and the recommendations of which will guide further action by Oxfam;

- changing policies, practices and culture within Oxfam, including significantly increasing our investment in safeguarding and in gender training and support;

- working with others across the humanitarian and development sector, including on efforts to reform recruitment and vetting processes to prevent offenders from moving between organizations.

For full detail on our approach, please see our 10 point action plan. 


\section{OXFAM GB'S COMMITMENTS}

As an organization that is working to enable women to realize their rights Oxfam GB is determined to build a fairer and more equal world for everyone - and, of course, that starts here, with us. Oxfam simply should not have a gender pay gap and should aim to achieve a zero pay gap. However, it is not simple, as:

- this is a complex issue that has multiple interlinked factors, some of which are within Oxfam's control and some are due to broader social norms that need to be challenged;

- steps to deliver long-term change could, in the short term, widen the gender pay gap. For example, if we promote more women in information systems roles through training programmes, this will initially mean more women in junior information systems roles, thus widening the gap;

- we need to collect better data and more disaggregated data internally to inform our approach.

Therefore, we have set a 2-year timeframe to address key areas of concern and to increase our understanding before setting longer term targets. This section brings together the commitments from the previous sections to provide a clear plan of action.

\section{GENDERED LEADERSHIP}

\section{Our commitment to increase representation of women in Oxfam leadership roles}

To address the low representation of women at director level, the Leadership Team has committed to taking the following actions:

- Working towards 50:50 representation, with an aim to maintain the range of $35 \%$ to $65 \%$ women. When recruiting for new Leadership Team roles, we commit to having shortlists with at least $50 \%$ of women.

- Reviewing the steps we need to take to ensure that Leadership Team roles (and also more roles at senior level) are designed in such a way that they are more likely to attract women.

- Ensuring at least $70 \%$ female participation in our leadership development programmes.

- Continuing to embed Oxfam GB's feminist leadership model through all our leadership development work, including specific sessions with the Leadership Team and a Senior Gender Leadership programme to target senior staff.

\section{Our commitment to support the promotion of women into senior positions}

- We will continue our Gender Leadership programme, encouraging men and women to take part.

- We will continue to include content covering issues such as bias, assumptions, diversity and inclusion in our development offer.

- We will provide resources on CV and interview preparation for all staff, and specific resources for women to support them with career progression.

- In Trading, there are several management development activities planned for 2018/19 - for all middle and senior managers, including refresher training around accountability for managing people and managing risk. Training materials and content will be reviewed to ensure that they address gender and diversity.

\section{Our commitment to address gender bias in recruitment}

- We will track how many roles are advertised as potential part-time roles, job shares and/or offering flexible hours.

- We will ensure that all newly recruited managers have undergone mandatory recruitment training as soon as possible.

- We will track starting pay for men and women.

- We will implement a pilot to align our recruitment for senior leadership positions with our leadership approach, with a strong diversity and inclusion focus. This should yield further learning for our wider recruitment processes.

-We will incorporate flexible working into our recruitment training. 


\section{UNPAID CARE WORK}

\section{Our commitment to improve provision for maternity, paternity and adoption leave}

- We will collect and analyse data on the number of staff taking maternity, paternity and adoption leave.

- We will analyse recent data and gather further qualitative data on men and women returning to work after maternity, paternity and adoption leave, and use this data to inform how we shape our support offer for parents before they take leave and after they return from leave.

- We will design and deliver a communication strategy to ensure that employees are aware of what support is available and how to access it.

-We will introduce enhanced shared parental leave pay from April 2018, to encourage and support more men to take time out for childcare responsibilities.

\section{Our commitment to improve our flexible working offer}

To understand where we can focus our efforts in future, we will:

- analyse data on extra hours worked for full-time and part-time staff, by grade and gender, through an annual staff survey;

- seek to understand and address the negative pay gap for part-time men with the aim to encourage more men to work part-time if they wish to;

- analyse promotions between grades for part-time versus full-time staff, by gender;

- collate and analyse data on how Oxfam staff use flexible working, and if and how requests are being refused, through an annual staff survey;

- analyse flexible working for women and men on fixed-term contracts compared with open-ended contracts via an annual staff survey;

- use the above analyses to disaggregate data for women over 40 to help us understand the significant pay gap for this group.

Steps to further support our flexible work culture:

- We will develop additional resources on flexible working for all staff and put these on our intranet. This will include top tips for flexible working, short stories and resources, and a guide to job-sharing. These will also be directly linked into our Flexible Working Policy so that those employees exploring flexible working options can see positive examples and success stories. We will continue regular communications for managers and staff on our commitment to support flexible working.

\section{Our commitment to supporting employees' mental health and self-care}

- We will implement training for 16 of our HR Business Partners, who directly support line managers in mental health first aid, by March 2018, in collaboration with Mind.

-We will continue to run our resilience webinar, which covers self-care and how to support others. It is accessible to all staff. Resilience will continue to be part of our leadership development offer. 


\section{GENDERED JOBS}

\section{Our commitment for future action on Trading roles}

-We are committed to understanding why our volunteering and shop roles attract more women than men, and withhold judgement about whether this should give cause for concern until we know more.

\section{Our commitment to improving women's representation in the Information Systems department}

- We will continue working to drive awareness and influencing around gender equality.

\section{Our commitment to helping more women move out of administrative roles}

- We will collect and analyse data on promotions from within the administrative level and use this analysis to inform next steps.

\section{SEXUAL HARASSMENT AND ABUSE}

\section{Our commitment to strengthen our work on sexual harassment and abuse in the workplace}

Our commitments have been agreed by the Oxfam Leadership Team. We will follow this plan and continue to listen and learn to ensure a comprehensive and accountable response from Oxfam around the world, which will lead to deep-rooted and lasting change.

Our actions focus on:

- demonstrating a meaningful commitment to transparency and accountability, including through the establishment of an independent commission to review our past and current work - the findings of which will be public, and the recommendations of which will guide further action by Oxfam;

- changing policies, practices and culture within Oxfam, including significantly increasing our investment in safeguarding and in gender training and support;

- working with others across the humanitarian and development sector, including on efforts to reform recruitment and vetting processes to prevent offenders from moving between organizations.

For full detail on our approach, please see our 10-point action plan. 


\section{Oxfam GB's Gender Pay Gap Report}

\section{REFERENCES}

${ }^{1}$ World Economic Forum (2016). Global Gender Gap Report. Retrieved 11 January 2018, from http://reports.weforum.org/global-gender-gap-report-2016/ progress-over-time/

2 See Oxfam GB's website for updates on the action plan: https://www.oxfam.org.uk/what-we-do/about-us/stamping-out-abuse?intcmp=HPWWLWP stampingoutabuse

${ }^{3}$ Equality and Human Rights Commission (2017). What is the difference between the gender pay gap and equal pay? Retrieved 6 March 2018, from https:// www.equalityhumanrights.com/en/advice-and-guidance/what-difference-between-gender-pay-gap-and-equal-pay

${ }^{4}$ Office for National Statistics (no date). Gender pay differences.. Retrieved 6 March 2018, from https://www.ons.gov.uk/employmentandlabourmarket/ peopleinwork/earningsandworkinghours/bulletins/annualsurveyofhoursandearnings/2017provisionaland2016revisedresults\#gender-pay-differences

${ }^{5}$ Equality and Human Rights Commission (2017). What is the difference between the gender pay gap and equal pay? Op. cit.

${ }^{6}$ 0. Khan. (2018). Employers admit there's a gender pay gap. What about race? The Guardian. https://www.theguardian.com/commentisfree/2018/ mar/04/employers-gender-pay-gap-race-ethnic-minority

7 J. Klugman, L. Hanmer, S. Twigg, T. Hasan, J. McCleary-Sills, J. Santamaria (2014). Voice and Agency: Empowering Women and Girls for Shared Prosperity. Washington DC: The World Bank.

${ }^{8}$ Women in National Parliaments website. Retrieved 6 March 2018, from http://archive.ipu.org/wmn-e/world.htm

${ }^{9}$ Fortune website. These Are the Women CE0s Leading Fortune 500 Companies. Retrieved 6 March 2018, from http://fortune.com/2017/06/07/ fortune-500-women-ceos/

${ }^{10}$ The Fawcett Society website. Value care work. Retrieved 6 March 2018, from https://www.fawcettsociety.org.uk/value-care-work.

${ }^{11}$ The Open University (2011). Proper men, proper women: gender roles in contemporary UK society. Retrieved 6 March 2018, from http://www.open.edu/ openlearn/body-mind/proper-men-proper-women-gender-roles-contemporary-uk-society. See also R. Pearse and R. Connell (2016). Gender Norms and the Economy: Insights from Social Research. Feminist Economics, 22(1), 30-53. http://www.tandfonline.com/doi/ full/10.1080/13545701.2015.1078485?src=recsys

${ }^{12}$ The London School of Economics and Political Science. Gender, Inequality and Power Commission. Retrieved 6 March 2018, from http://www.lse.ac.uk/ gender/research/Gender-Inequality-and-Power-Commission

${ }^{13}$ The 56 employees included in our statutory reporting work identified based on whether the employment relationship suggests a stronger connection to Great Britain and British employment law than to the law of any other country.

${ }^{14}$ Over the past few years Oxfam GB has committed to playing a leading role in building the Oxfam global confederation. This will enable us to share resources, save money, be more effective, and ensure that countries in the global South feel greater local ownership of our work. Our earlier commitments are now being translated into action, and we have taken huge steps towards bringing our regional and country teams under one management structure. This internationalization process has been a challenging journey, as it involves Oxfam GB giving up power. Now, we share responsibility with others, and act as a partner rather than a manager. Despite the challenges, we are making significant progress. In 2016, we transferred half our country offices to a shared Oxfam management structure, and we have ambitious plans to transfer the remainder during $2017 / 18$.

${ }^{15}$ S. Batliwala (2011). Feminist Leadership for Social Transformation: Clearing the Conceptual Cloud. This conceptual model is fundamental to the future framework of Oxfam leadership. Its foundational contributions are 1) Oxfam leadership as transformational leadership and contributing to social change (leadership purpose and values), 2) transformational leadership must deal with power and internal power dynamics as essential elements of our politics and purpose, and 3) focus on self-awareness and building leadership identity are critical to achieving gains in southern and women leadership at all levels.

${ }^{16}$ See note 23.

17 These figures are based on annual full-time equivalent annual contractual pay for all UK employees based on our 1 April PME report 2017.

${ }^{18}$ ONS (2017). Annual survey of hours and earnings. Retrieved from https://www.ons.gov.uk/employmentandlabourmarket/peopleinwork/ earningsandworkinghours/bulletins/annualsurveyofhoursandearnings/2017provisionaland2016revisedresults\#gender-pay-differences

${ }^{19}$ This data is based full-time equivalent annual contractual pay for all UK employees based on our 1 April PME report

${ }^{20}$ ONS dataset 'Understanding the gender pay gap, UK, Annual Survey of Hours and Earning'. Retrieved 6 March 2018, from https://www.ons.gov.uk/ employmentandlabourmarket/peopleinwork/earningsandworkinghours/datasets/ understandingthegenderpaygapukannualsurveyofhoursandearningdataset

${ }^{21}$ Grade $\mathrm{C}$ and above.

${ }^{22}$ International Labour Organization (ILO) and South-East Asia and the Pacific Multidisciplinary Advisory Team (SEAPAT). OnLine Gender Learning $\delta$ Information Module. Unit 1: A conceptual framework for gender analysis and planning. Retrieved 6 March 2018, from http://www.ilo.org/public/english/ region/asro/mdtmanila/training/unitl/groles.htm

${ }^{23}$ ONS dataset EMP04. Employment by occupation. https://www.ons.gov.uk/employmentandlabourmarket/peopleinwork/employmentandemployeetypes/ datasets/employmentbyoccupationemp04

${ }^{24}$ National statistics data is based on shop keepers and proprietors and excludes deputy shop managers.

${ }^{25}$ Xpert HR Voluntary Sector Salary Survey 2017. Retrieved 6 March 2018, from http://www.xperthr.co.uk/salary-surveys/voluntary-sector/150832/

${ }^{26}$ ONS dataset EMP04: Employment by occupation. Op. cit. 


\section{Acknowledgements}

This report was written by Alex Cole-Hamilton, Head of Corporate Responsibility, Oxfam GB with significant input from Tanya Hill, Head of Reward, Nikki Van Der Gaag, Director of Women's Rights and Gender Justice, Fenella Porter, Gender Policy Advisor and Yamina Himeur, Head of Talent and Resourcing. We acknowledge invaluable feedback and suggestions from Mary-Ann Stephenson, Director of the Women's Budget Group, the UNITE Oxfam Branch, the Oxfam Independent Union, and our Women's Leadership Network. We would also like to thank Oxfam GB staff members Alex Maitland, Anne Webb, Penny Fowler, Hannah Claire, Anna Coryndon, Nikki Glover, Sophie Brill, Thomas Instone, Claire Barber and Oxfam International staff Saranga Sri-Nammuni.

\section{(c) Oxfam Great Britain March 2018}

This publication is copyright but the text may be used free of charge for the purposes of advocacy, campaigning, education, and research, provided that the source is acknowledged in full. The copyright holder requests that all such use be registered with them for impact assessment purposes. For copying in any other circumstances, or for re-use in other publications, or for translation or adaptation, permission must be secured and a fee may be charged. Email policyandpractice@oxfam.org.uk.

The information in this publication is correct at the time of going to press.

Published by Oxfam GB under ISBN 978-1-78748-214-2 in March 2018. DOI: 10.21201/2017.2142

Oxfam GB, Oxfam House, John Smith Drive, Cowley, Oxford, OX4 2JY, UK.

\section{WENT

